\title{
On the Road Again: Returning to Conferences
}

\author{
Adam Wax \\ Editor-in-Chief
}

The last conference I went to was Photonics West in February 2020. It was a great time, as always. We enjoyed San Francisco, went to a great trade show, and of course, saw lots of oral presentations. In person. Since then, I have logged hundreds of hours on Zoom as we all learned how to work from home. Some of these hours were in virtual conferences. I gave talks on a wide range of topics, including my group's research, advances at my company, and how to give talks on Zoom. At first, my virtual talks were earnest and enthusiastic. But as we all found out, without live feedback from an audience, it just didn't feel the same. Typically, people watching virtual talks do not have their cameras on, and it can feel like showing slides and speaking to a still screen of squares. Sometimes, there was a Q\&A, offering some chance for interaction, but there definitely wasn't the chance for a back-and-forth discussion. Only after we lived without it did I realize that this was my favorite part of the academic talks. We also did without the chance meeting in the hallway between sessions with a colleague we hadn't seen in a while. Although we did have a few virtual happy hours along the way, we also surely missed sitting with our friends and colleagues after long conference days, reviewing the great talks we saw, and dishing the dirt on who we had seen and heard about.

I'm glad to say that conference travel will be starting up again soon. The next SPIE conference on my calendar is Optics + Photonics 2021 in San Diego in August. Needless to say, I'm looking forward to it. There will be a great symposium on Machine Learning, chaired by Drs. Zelinski, Taha Howe, Awaal, and OE's own Dr. Khan Iftekharuddin. The conference on Lens Design and Optical Engineering will be in its 22nd edition, chaired by Drs. Johnson, Mahajan, Thibault, Bunch, and Sun. This topic was the subject of a special section in the May 2021 issue of Optical Engineering.

I know that not everyone will be ready or able to travel by August, and there are still a lot of details to work through. But if we don't get the chance to see you then, there are more and more conference dates lining up for the year ahead. I'm glad to know that calls for papers are in preparation for Photonics West 2022 and that a return to San Francisco is highly likely.

As we all return to conferences, I'd like to talk about turning your SPIE conference presentation into a submission to Optical Engineering or another SPIE journal. In many ways, this is a unique opportunity for you to build on the effort you've put into your presentation or proceedings paper to convert it to a peer-reviewed publication. Since SPIE publication policy allows for manuscript submissions based partly or entirely on an SPIE proceedings paper, there's no risk of double publication or self-plagiarism. This is because we recognize the different, complementary roles of these paper types: While a proceedings paper typically gives an update on the state of your work at the time of the conference, a subsequent peer-reviewed manuscript gives a more complete overview that provides an enduring contribution to the literature. As new work is rolled out at these upcoming conferences, we would like to encourage conference presenters to polish up their proceedings papers for submission to Optical Engineering.

(C) 2021 Society of Photo-Optical Instrumentation Engineers (SPIE) 